\title{
RESEARCH
}

Open Access

\section{Challenges for the surgical capacity building of township hospitals among the Central China: a retrospective study}

\author{
Zhong $\mathrm{Li}^{1 \dagger}$, Jian Yang ${ }^{1,2+}$, Yue Wu', Zijin Pan ${ }^{1}$, Xiaoqun He${ }^{1}$, Boyang $\mathrm{Li}^{1}$ and Liang Zhang ${ }^{*}$
}

\begin{abstract}
Background: China's rapid transition in healthcare service system has posed considerable challenges for the primary care system. Little is known regarding the capacity of township hospitals (THs) to deliver surgical care in rural China with over 600 million lives. We aimed to ascertain its current performance, barriers, and summary lessons for its re-building in central China.

Methods: This study was conducted in four counties from two provinces in central China. The New Rural Cooperative Medical System (NRCMS) claim data from two counties in Hubei province was analyzed to describe the current situation of surgical care provision. Based on previous studies, self-administered questionnaire was established to collect key indicators from 60 THs from 2011 to 2015, and social and economic statuses of the sampling townships were collected from the local statistical yearbook. Semi-structured interviews were conducted among seven key administrators in the THs that did not provide appendectomy care in 2015. Determinants of appendectomy care provision were examined using a negative binominal regression model.
\end{abstract}

Results: First, with the rapid increase in inpatient services provided by the THs, their proportion of surgical service provision has been nibbled by out-of-county facilities. Second, although DY achieved a stable performance, the total amount of appendectomy provided by the 60 THs decreased to 589 in 2015 from 1389 in 2011. Moreover, their proportion reduced to $26.77 \%$ in 2015 from $41.84 \%$ in 2012. Third, an increasing number of THs did not provide appendectomy in 2015, with the shortage of anesthesiologists and equipment as the most mentioned reasons (46.43\%). Estimation results from the negative binomial model indicated that the annual average per capita disposable income and tightly integrated delivery networks (IDNs) negatively affected the amount of appendectomy provided by THs. By contrast, the probability of appendectomy provision by THs was increased by performance-related payment (PRP). Out-of-pocket (OOP) cost gap of appendectomy services between the two different levels of facilities, payment method, and the size of THs presented no observable improvement to the likelihood of appendectomy care in THs.

Conclusion: The county-level health system did not effectively respond to the continuously increasing surgical care need. The surgical capacity of THs declined with the surgical patterns' simplistic and quantity reduction. Deficits and critical challenges for surgical capacity building in central China were identified, including shortage of human resources and medical equipment and increasing income. Moreover, tight IDNs do not temporarily achieve capacity building. Therefore, the reimbursement rate should be further ranged, and physicians should be incentivized appropriately. The administrators, policy makers, and medical staff of THs should be aware of these findings owing to the potential benefits for the capacity building of the rural healthcare system.

Keywords: Township hospital, Surgical capacity, Pay for performance, Integrated delivery networks, Rural China

\footnotetext{
* Correspondence: zhangliang@mails.tjmu.edu.cn

'Equal contributors

${ }^{1}$ School of Medicine and Health Management, Tongji Medical College,

Huazhong University of Science and Technology, No 13 Hangkong Road,

Qiaokou District Wuhan, Hubei 430030, China

Full list of author information is available at the end of the article
}

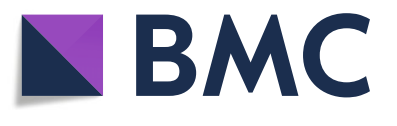

(c) The Author(s). 2018 Open Access This article is distributed under the terms of the Creative Commons Attribution 4.0 International License (http://creativecommons.org/licenses/by/4.0/), which permits unrestricted use, distribution, and reproduction in any medium, provided you give appropriate credit to the original author(s) and the source, provide a link to the Creative Commons license, and indicate if changes were made. The Creative Commons Public Domain Dedication waiver (http://creativecommons.org/publicdomain/zero/1.0/) applies to the data made available in this article, unless otherwise stated. 


\section{Background}

Injury caused numerous disability and mortality cases globally, especially in conflict-affected or resourcelimited regions [1, 2]. Approximately $11 \%$ of the total disability-adjusted life year worldwide could be attributed to the surgical disease burden [3]. As a significant part of global health $[4,5]$, evidence proved that essential surgical care provision could effectively satisfy the demand of local residents [6-10] and benefit universal health coverage $[11,12]$. However, many low-and middle-income countries (LMICs) could still not provide essential surgical services, mainly caused by limited health human resources, logistics, medicine, infrastructure, equipment, and supplies [5, 13-16]. Such restriction further prevented two billion people from gaining access to surgical and anesthesia care [1, 14, 17]. The accessibility of surgical care varied markedly worldwide $[12,18,19]$.

Although no standard existed for the required capabilities of the first-level hospitals, the caesarean delivery, laparotomy, and open fractures are widely recognized as the bellwether procedures of their essential surgical care [18, 20]. In addition, medical staffs were trained to provide these services worldwide [10, 21, 22]. In 2004, WHO launched the Emergency and Essential Surgical Care Project to strengthen the availability of essential surgical care, including burns, orthopedics, obstetrical acute conditions, and lower abdominal diseases [4, 23-25]. This project achieved huge success on the surgical care provision in the primary care system and proved cost- effective $[12,26]$.

After the establishment of New China, the threetiered health delivery network was quickly formed, led by the county-level hospitals (CLHs) and composed of THs and village clinics [27]. Different institutions coordinated with one another and provided healthcare services together. The village clinics, as the cornerstone of the network, provide essential services to enrollers through the Cooperative Medical System. THs and CLHs are responsible for the continuing education and technical assistance for the medical staff in THs. With the huge changes in both population patterns and disease spectra, the following decades have witnessed its significant achievements [28-33]. However, from the Reform and Opening-up, the two-referral services were heavily damaged and residents freely jumped to high level facilities for healthcare services. Different institutions are pursuing their own interests. A poorly equipped referral system, such as other LMICs, caused many problems [17]. Issues included surgical services neglected in the primary care facilities, which are necessary to encourage the provision of related services by the primary care system [34]. In addition, the dysfunction of THs caused an increasingly pressing fragmented three- tiered healthcare delivery system [35]. First, secondary and tertiary hospitals have excessively provided services outside its functional orientation under the side effects of a market-oriented system [36]. Second, the patients' distrust on primary care facilities has also caused its poor performance [37]. According to the fifth National Health Services Survey and China Health Statistic Yearbook, the proportion of hospitalization in THs decreased to $29.8 \%$ in 2013 from $36.6 \%$ in 2008, whereas the proportion of the CLHs increased from $50.0 \%$ to $55.7 \%$. The beds of THs in the entire health system for the surgeon, gynecology, and obstetrics in THs decreased from 17. $58 \%$ and $12.81 \%$ in 2011 to $15.9 \%$ and $10.23 \%$ in 2015 , respectively [38, 39]. Third, medical staffs in the primary facilities were not fully motivated, attending to be more or less single-minded on the chronic disease management services [40-42]. Moreover, compared with urban areas providing a broader range of surgical services, geographic disparities startlingly exist with respect to access to healthcare services in rural China [43]. Hence, surgical capacity and its availability in the rural areas must be urgently improved, considering there still existing 603 million lives [4, 44].

Since 2009, the New Healthcare Reform has strengthened the capacity building of the grassroots facilities. The amount of 100 billion RMB was placed into county-level and below facilities [45]. With the implementation of separating revenue and expenditure (SRE), pay for performance (P4P), zero mark-up of medicine, specific medical students for the rural areas [46], ranged reimbursement ratio, and IDNs [47], the quality of care and patients' satisfaction improved [48], but a few of the above policies caused burnout or mobility among the medical staffs [36]. In recent years, approximately $30 \%$ of physicians' salaries, which were previously linked with the title, working years, and education background, were linked with the amount of service provision in certain THs to counteract the egalitarianism caused by the SRE and P4P. To distinguish it from P4P in this study, we reported it as PRP.

Abundant research has highlighted the role of incentives, IDNs in the healthcare reform, especially chronic disease management [48-50]. However, existing research has ignored the role of surgical care in the Chinese rural health system. Moreover, no exact data could present an evolution of surgical care provision or have explored its determinants with the increasing number of surgical care necessary. This study aims to quantify the surgical capacity from the providers' perspective and the patients' flow and to identify its deficits and challenges in multiple channels with the appendectomy provision 
from 2011 to 2015 [34]. Such goal acts as the first step to promote capacity building in the rural healthcare system.

\section{Methods}

\section{Study sample}

The selection of 60 THs from four counties was conducted based on a multistage stratified purposive sampling method [51-53]. First, the six provinces, namely, Shanxi (23/31), Henan (17/31), Anhui (18/31) , Hubei (10/31), Jiangxi (13/31), and Hunan (15/31), were classified into two groups according to the ranking of per capita disposal income in 2015. We then randomly selected two provinces from the two groups. Second, given the huge county-level variations within the province on the socio-economic development, 102 county-level regions in Hubei and 158 county-level regions in Henan were divided into two groups based on the per capita disposal income. Macheng (MC), Zhijiang (ZJ), and Dangyang (DY) in Hubei, and $\mathrm{Xi}(\mathrm{XI})$ in Henan were then selected (see Fig. 1 and Table 1). Finally, all 60 THs were selected to finish the self-administrated questionnaire. Seven THs that did not provide the appendectomy care were selected for our semi-structured interviews (see Table 2).

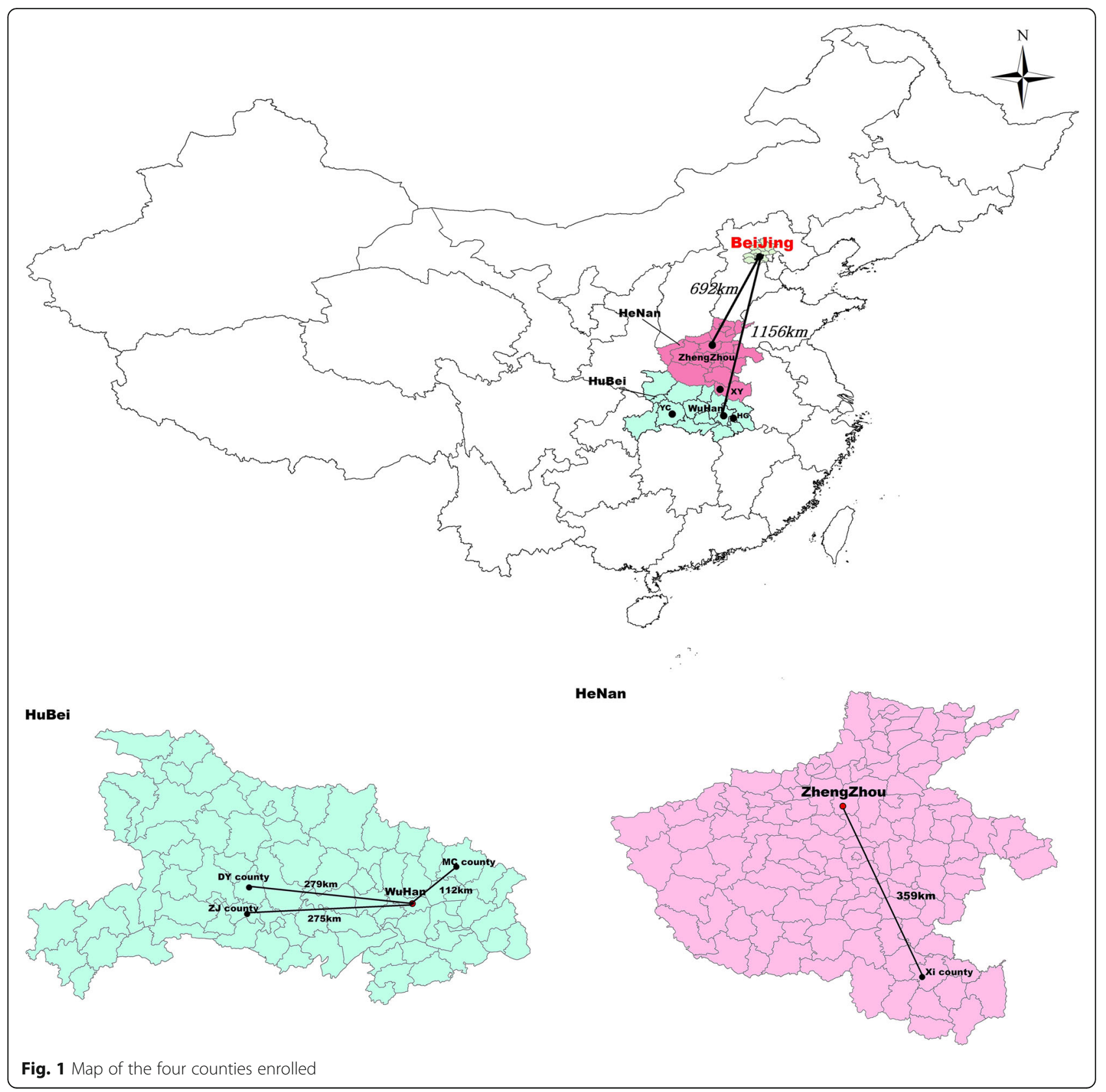


Table 1 Social economic status and other characteristic of sampling counties in 2015

\begin{tabular}{|c|c|c|c|c|}
\hline Characteristic & $X I$ & MC & DY & ZJ \\
\hline Income level & Undeveloped & Undeveloped & developed & developed \\
\hline Number of THs & 21 & 21 & 10 & 8 \\
\hline Annual average per capita disposable income ( $¥)$ & 8516.71 & 8080.86 & $15,869.7$ & $15,578.88$ \\
\hline Number of outpatients & $35,750.43$ & $67,369.1$ & $51,201.4$ & $39,350.13$ \\
\hline Number of inpatients & 1578.76 & 2829.86 & 2195.8 & 2480.25 \\
\hline Average time to the THs (min) & 23 & 354 & 33 & 28 \\
\hline Average time to the local People hospital (min) & 46 & 50 & 35 & 49 \\
\hline Average cost of appendicitis per 1000 ( $¥)$ & 2312.95 & 1447.99 & 1954.31 & 2980.78 \\
\hline Average cost gap between CLHs and THs of appendicitis ( $¥)$ & 819.62 & 1233.86 & 1784.7 & 1449.88 \\
\hline Average number of anesthesiologist per 1000 & 0.81 & 1.52 & 1.1 & 1.38 \\
\hline Average number of surgeon per 1000 & 2.38 & 2.57 & 3 & 2.63 \\
\hline
\end{tabular}

Note: Time to the THs and local People hospital using the car was estimated with the Baidu Map

\section{Data collection procedure}

Based on previous studies [54, 55], the questionnaire comprised the following three parts: 1) social and economic statuses of the sampling townships, including total population and annual per capital disposable income; 2) basic information of $\mathrm{THs}$, including the numbers of anesthesiologists and nurses, medicine and anesthetics or surgical facilities and the amount of appendectomy provision; 3) Institutional operation, including the type of IDNs, size of facilities, PRP or not, average OOP cost gap between the townshipcounty hospitals, and payment method. This survey was conducted from August 2016 to October 2016. First, the NRCMS claim data and related policies from 1st January 2011 to 31st December 2015 were retrieved, except from the claim data of MC from 1st January 2011 to 31st December 2011. Second, the socio-economic characterization of the sampling townships was collected from the local statistical yearbooks. The self-developed questionnaire was used to collect basic information and institutional operation the $60 \mathrm{THs}$ from the deputy dean or head of the surgical department. Subsequently, the semi-structured interviews were conducted among the administrators of the seven THs that did not provide appendectomy care by the principal investigator.

\section{Statistical analysis}

First, descriptive analysis was applied in the claim and survey data to visualize the patient flow within the county-level healthcare delivery system. We used the $x^{2}$ or Cochran-Armitage trend test to determine statistical significance. Second, we summarized the potential determinants of the phenomenon behind why certain THs did not provide appendectomy. Third, considering the over-dispersed appendectomy provision, a negative binomial regression model was used to investigate its determinants [56-58] (see Table 3), which were extensively used in similar studies [59-61]. Cost data were adjusted by the CPI of the 2015 National Health Statistic Yearbook [39]. Data were managed by Epidata 3.0 and analyzed by Stata 13.0 (Stata Corp LP, College Station, TX, USA). $P$-value of $<0.05$ was defined as statistical significance.

\section{Results \\ Characteristic of surgical care and appendectomy provision}

Limited to data quality and accessibility, the NRCMS claim data of the DY and ZJ were selected to sketch the patient flow. From 2011 to 2015, a proportion of the inpatient services provided by THs in DY increased from $33.48 \%$ to $38.86 \%(P<0.001)$, whereas that of $\mathrm{ZJ}$

Table 2 Respondents' characteristic of the self-administrated questionnaires and semi-structured interviews

\begin{tabular}{|c|c|c|c|}
\hline \multicolumn{2}{|c|}{ Characteristic } & \multirow{2}{*}{$\begin{array}{l}\text { Respondents of the self-administrated } \\
\text { questionnaire }(N=60) \\
47\end{array}$} & \multirow{2}{*}{$\begin{array}{l}\text { Respondents of semi-structured } \\
\text { interviews }(N=7) \\
6\end{array}$} \\
\hline Gender & male & & \\
\hline Age(years) & & $44.41 \pm 4.70$ & $44.56 \pm 5.23$ \\
\hline \multicolumn{2}{|c|}{ Years practicing as physicians } & $24.36 \pm 4.79$ & $23.57 \pm 5.48$ \\
\hline \multirow[t]{2}{*}{ Education } & Undergraduate & 27 & 3 \\
\hline & College and above & 33 & 4 \\
\hline
\end{tabular}


decreased from $44.00 \%$ to $42.63 \%(\mathrm{P}<0.001)$ (see Fig. 2). The inpatient services provided by out-of-county hospitals grew rapidly, accounting for $14.75 \%$ and $17.23 \%(P<0.001)$. However, under rapid growth in the surgical service provision among the three-level facilities, the proportion of THs' provision declined to $12.18 \%$ and $34.06 \%$ from $19.39 \%(P<0.001)$ and $36.38 \%(P<0.001)$, respectively. The out-of-county facilities are rapidly nibbling their proportion, accounting for $31.03 \%(\mathrm{P}<0.001)$ and $26.91 \%(\mathrm{P}<0.001)$ in 2015 , respectively. Moreover, the proportion of inpatients utilizing surgical care in the THs decreased to $11.16 \%(\mathrm{P}<0.001)$ and 25.82\% $(\mathrm{P}<0.001)$. Out-of-county facilities increased dramatically to $31.03 \%(\mathrm{P}<0.001)$ and $26.91 \%(\mathrm{P}<0.001)$ from $13.61 \%$ and $10.45 \%$, respectively.

The amount of appendectomy provided by the 60 THs has decreased to 589 in 2015 from 1389 in 2011 (see Fig. 3). Appendectomy of XI $(P<0.001)$, MC $(\mathrm{P}<0.001)$, and ZJ $(P=0.007)$ decreased from 619,264 , and 264 to 183,146 , and 147 cases, respectively. By contrast, DY's performance was stable $(P=0.862)$. The number of THs that cannot provide appendectomy increased to $7(11.67 \%)$ in 2015 from $5(8.33 \%)$ in $2011 \quad(P=0.5428)$. The number of THs, which does not provide appendectomy even if equipped with related resources increased to $9(15.00 \%)$ in 2015 from $1(1.67 \%)$ in $2011(P=0.0082)$.

\section{Determinants of the appendectomy care provision}

In 2015, seven THs cannot provide appendectomy services. Table 4 summarizes the most frequently emerging reasons. Shortage of anesthesiologists and equipment is apparently the most cited reasons, accounting for 46 . $43 \%$. The negative binominal regression model was conducted to explore determinants of appendectomy counts

Table 3 Variables description

\begin{tabular}{lllll}
\hline Variable & Maximum & Minimum & Mean & Std \\
\hline Noapp & 171 & 0 & 17 & 25 \\
size & 3 & 1 & 1.78 & 0.63 \\
income & 18,526 & 2267 & 8447 & 3486 \\
costgap & 3614 & 447 & 1177 & 398 \\
p4p & 1 & 0 & 0.69 & 0.46 \\
Payment & 3 & 1 & 1.8 & 0.55 \\
IDNs & 4 & 1 & 1.63 & 0.93 \\
\hline
\end{tabular}

Note: Noapp, the number of appendicitis provided by the township hospitals annually; Size can represent its inpatient and surgical services' capacity: street township hospitals $=1$, ordinary $\mathrm{TH} s=2$, central $\mathrm{TH} s=3$; Costgap, the difference between the average out-of-pocket cost of appendicitis in the THs and CLHs; The remuneration of medical staff are linked up with the healthcare services provision in a certain degree. Payment methods were composited with single-disease with abundant quota, single-disease with limited quota, fee for service. IDNs are vigorously promoted by the China government, the sampling THs were clustered as four types based its property right belongings and management form: no integration $=1$, tight integration $=2$, loose integration $=3$, merged integration $=4$ (see Table 3). According to the results of Hausman test (chi2 [8] $=5.00$, Prob > chi2 $=0.757$ ), we choose the random effect model [62]. As Table 5, the annual average per capita disposable income $(R R=0.892, P<0.001)$ negatively affected the TH's appendectomy provision. Effects of the OOP cost gap between the two different levels of facilities $(\mathrm{RR}=1.000, P=0.671)$ and payment method $\left(\mathrm{RR}_{\mathrm{SDLQ}}=0.871, P=0.146, \mathrm{RR}_{\mathrm{FFS}}=0.952, P=0.816\right)$ are statistically insignificant. Moreover, the size of THs did not improve the likelihood of appendectomy provision $\left(\mathrm{RR}_{\text {ordinary }}=0.527, P=0.170, \mathrm{RR}_{\text {central }}=0.664, P=0.401\right)$. The tight IDNs $(R R=0.444, P=0.006)$ negatively affected the appendectomy provision. By contrast, the PRP has significantly increased THs' probability of providing appendectomy care relative to the $\mathrm{P} 4 \mathrm{P}$ with egalitarianism $(R R=2.206, P=0.006)$.

\section{Discussion}

This study presents the dramatic decline in the quantity and proportion of surgical services by $\mathrm{THs}$, as countylevel surgical service provision continues to rise from 2011 to 2015. The importance of THs is gnawing away, and the expansion of CLHs occupied THs' space as the THs' main source of revenue changes from medical service provision to public health services [63]. Such situation is similar to the phenomenon of the largely missing surgical services from the early Medicare Accountable Care Organization in the USA [64]. This gap may be associated with the status of the medical staff in the THs, who seem "fuzzy" on their roles [40]. Moreover, an increasing number of THs are unwilling to provide surgical services, in line with previous studies in which ignorance of medical service provisions is caused by an overemphasis on the chronic disease management in China [47, 48]. The geographic disparity is also impressive. Given that the DY and ZJ counties had once been commended for its tiered healthcare delivery system by the State of Council, we could speculate that a few undeveloped counties may face other austere challenges, and the current situation would also negatively affect the medical quality [65]. In XI county, appendectomy care was included in the coordination care list to improve quality of care [36]. However, the practice did not promote surgical task sharing, which might be associated with the malposition of actual capacity. Extra support should be added on the clinical collaboration between the medical staff and may even require a long period to resolve the shortage, thereby enabling team-based capacity building [66]. A distorted distribution of health utilization in the CLHs resulted in considerable inefficiencies in terms of resource allocation. Overall, practitioners must urgently be well trained and retained to provide surgical services. 

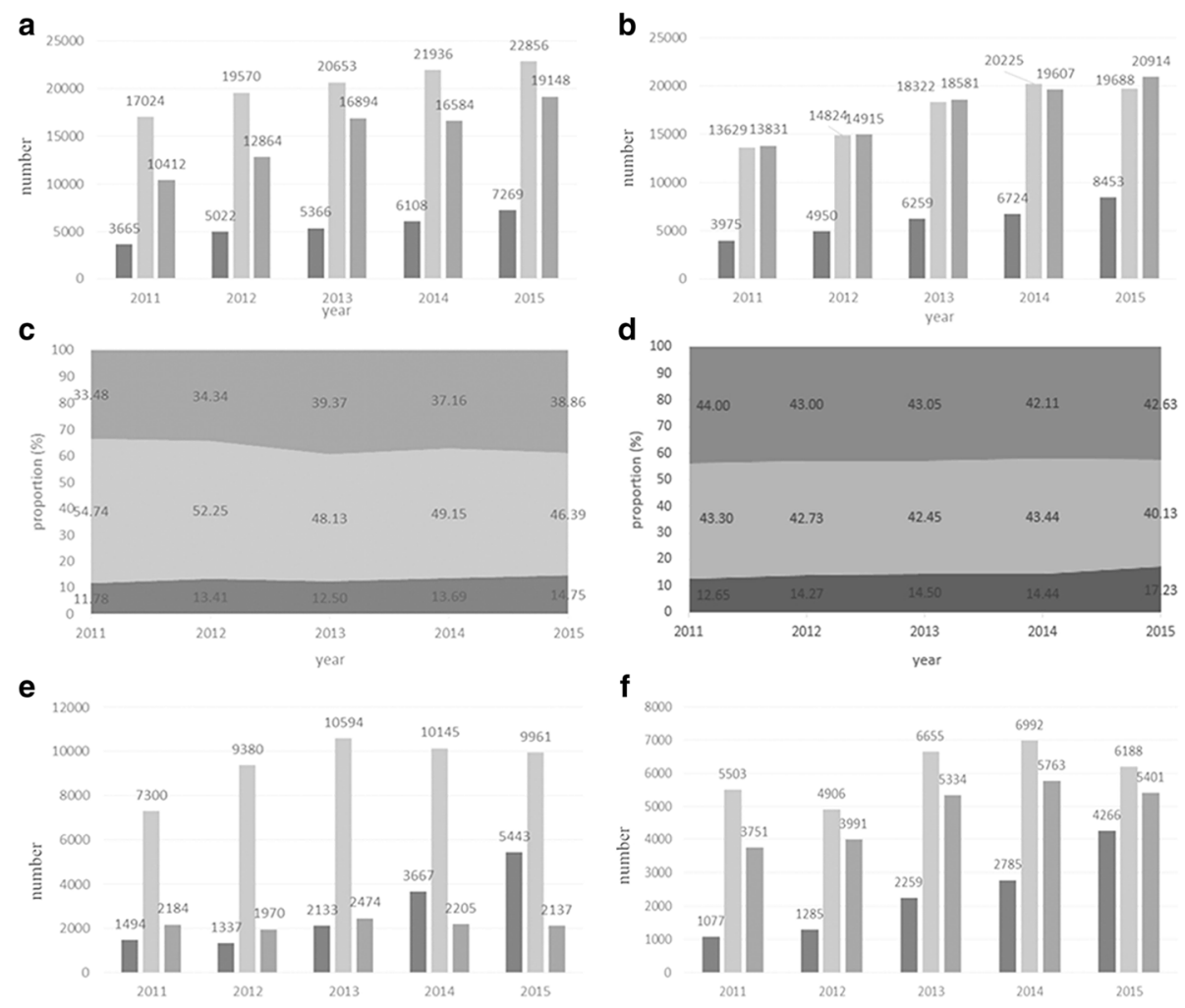

$\mathbf{f}$
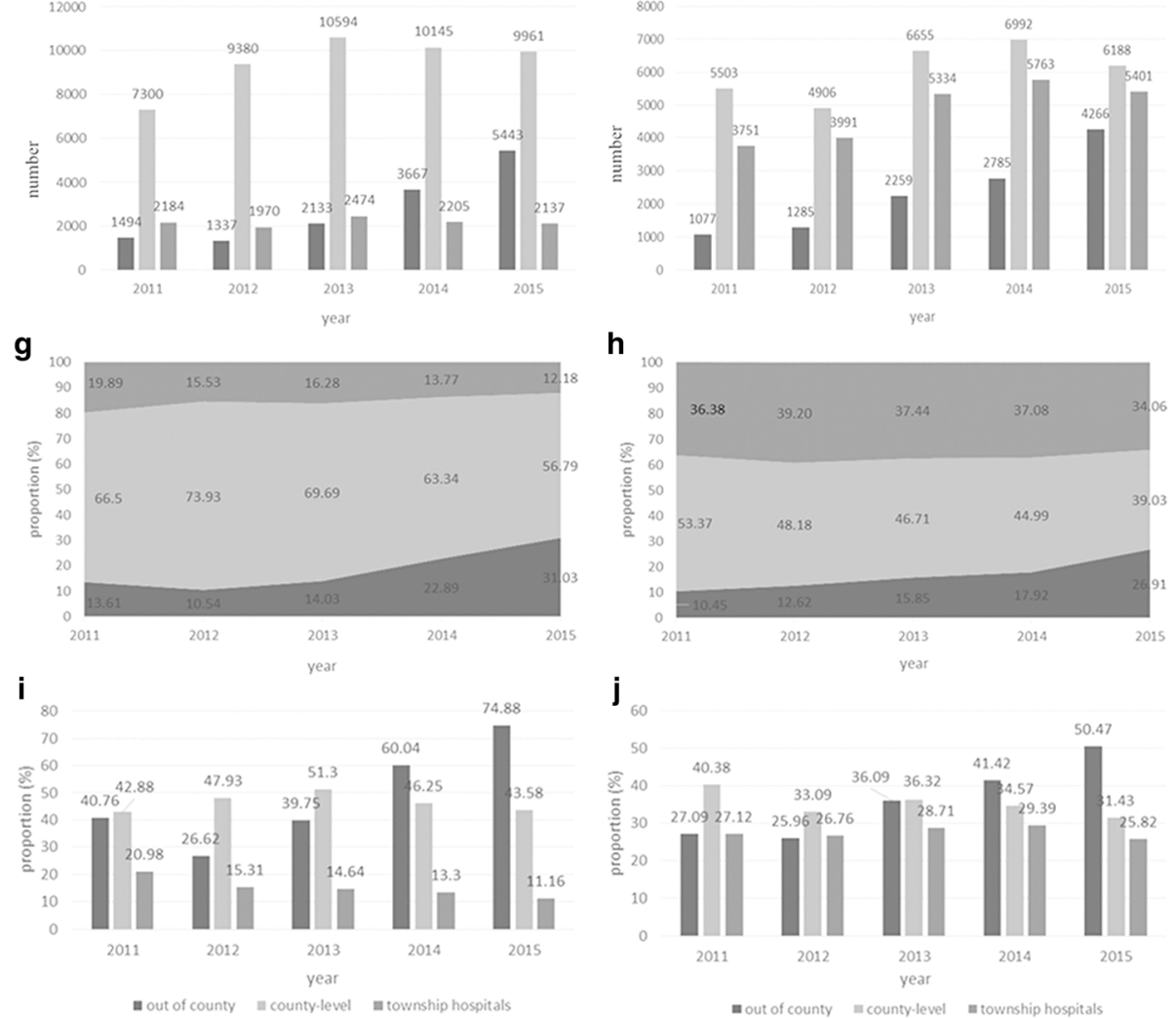

Fig. 2 Surgical care provision. Note: (a and $\mathbf{b})$ Inpatients care within the three-level facilities in DY and ZJ; (c and $\mathbf{d})$ Inpatients care proportion within the three-level facilities in DY $(P<0.001)$ and ZJ $(P<0.001)$; (e and $\mathbf{f})$ Surgical care in the three-level facilities in DY and ZJ; (g) (h) Surgical cares' proportion among the three-level facilities in DY $(P<0.001)$ and $Z J(P<0.001)$; (i and $\mathbf{j})$ Proportion of inpatients care utilized surgical services within the three-level facilities in DY $(P<0.001)$ and $Z J(P<0.001)$

Moreover, the essential medicine list should be progressively expanded [67].

When appendectomy was taken as an example to explore potential determinants, the panel data analysis demonstrates that appendectomy care provision by the THs was reduced with the increase in per capita disposable income. The OOP cost gap between THs and CLHs could not change the patients' behavior, in line with one study conducted in rural Gansu Province [68]. Similarly, this condition could also be explained by the awakening health literacy with increasing income [69]. Such scenario may aggravate 
a

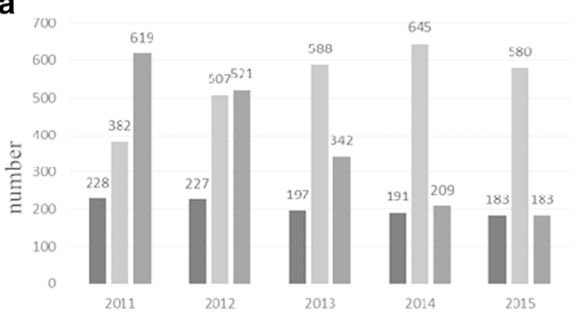

C

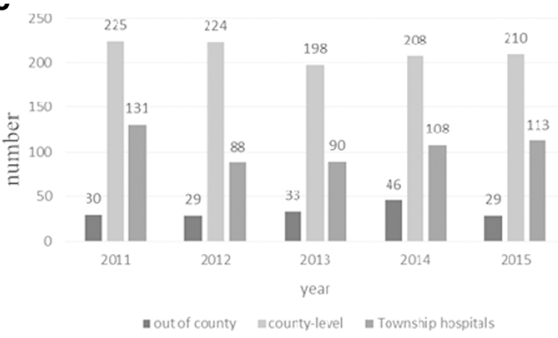

e

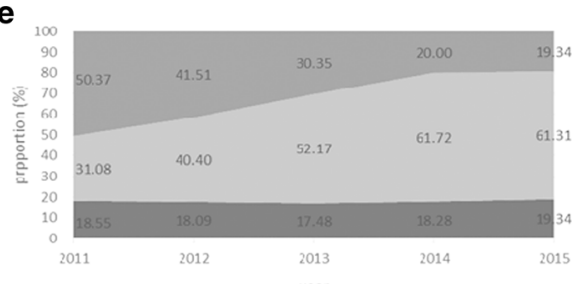

g

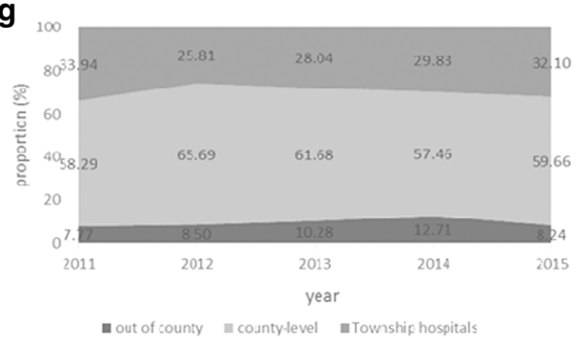

b

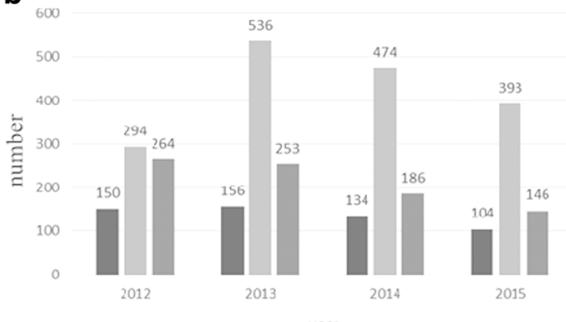

d

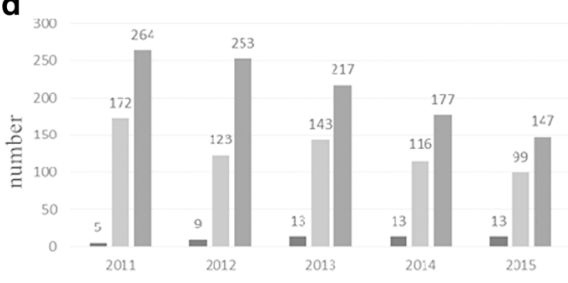

f

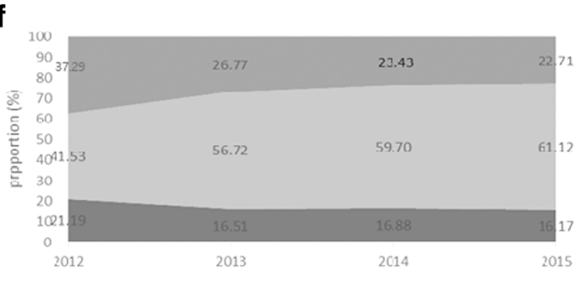

h

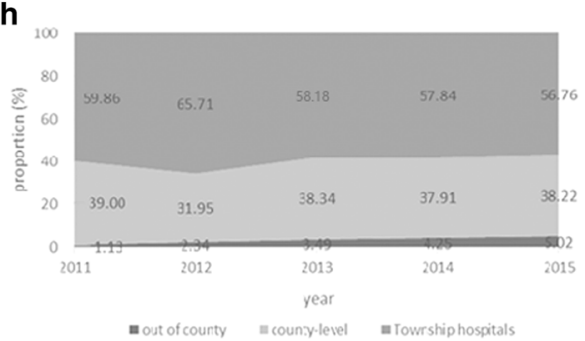

Fig. 3 Appendectomy care provision. Note: (a-d) Appendectomy care within the three-level facilities in XI, MC, DY and ZJ; (e-h) Appendectomy care proportion within the three-level facilities in XI $(P<0.001), M C(P<0.001)$, DY $(P=0.862)$ and $Z J(P=0.007)$

the growth of patients' OOP cost and local health spending and expand the disparities with respect to the benefits of health insurance between the poor and the rich [70]. As the main source of different levels of institutions [63], current payment methods failed to fully incentivize physicians in $\mathrm{THs}$ to provide appendectomy care, the higher quota reimbursement and FFS cannot encourage physicians to provide further services, reflecting the irrational incentives in the current insurance system. Moreover, with the

Table 4 Self-reported reasons of the 7 township hospitals administrators

\begin{tabular}{llll}
\hline Reasons & Frequency & Percent & Accumulative \% \\
\hline Shortage of anesthesiologist & 7 & 25.00 & 25.00 \\
Shortage of Medical apparatus and instruments & 6 & 21.43 & 46.43 \\
Shortage of surgeon & 4 & 14.29 & 60.72 \\
Shortage of nurse & 4 & 14.29 & 75.01 \\
Shortage of surgical facilities & 3 & 10.71 & 85.72 \\
Shortage of pharmaceutical capacity & 3 & 10.71 & 96.43 \\
Shortage of Inspection equipment & 1 & 3.57 & 100.00 \\
\hline
\end{tabular}


Table 5 Results of the negative binomial regression model

\begin{tabular}{|c|c|c|c|}
\hline \multicolumn{2}{|c|}{ Independent variable } & \multicolumn{2}{|l|}{ Random effect model } \\
\hline Income & & $\begin{array}{l}\text { IRR }(95 \% \text { Cl) } \\
0.897(0.853,0.943)\end{array}$ & $\begin{array}{l}P \\
<0.001\end{array}$ \\
\hline Costgap & & $1.000(1.000,1.000)$ & 0.671 \\
\hline \multirow[t]{3}{*}{ Size } & street THs\# & & \\
\hline & ordinary THs & $0.527(0.211,1.316)$ & 0.170 \\
\hline & central THs & $0.664(0.256,1.727)$ & 0.401 \\
\hline \multirow[t]{4}{*}{ IDNs } & No\# & & \\
\hline & Tight & $0.484(0.290,0.810)$ & 0.006 \\
\hline & Loose & $1.011(0.672,1.522)$ & 0.956 \\
\hline & Merged & $0.881(0.319,2.433)$ & 0.807 \\
\hline \multirow[t]{2}{*}{ PRP } & No\# & & \\
\hline & Yes & $2.305(1.570,3.384)$ & $<0.001$ \\
\hline \multirow[t]{3}{*}{ Payment } & SDAQ\# & & \\
\hline & SDLQ & $0.868(0.731,1.031)$ & 0.106 \\
\hline & FFS & $0.939(0.638,1.382)$ & 0.749 \\
\hline \multicolumn{2}{|l|}{ Constant } & $23.364(7.920,68.921)$ & \\
\hline \multicolumn{2}{|c|}{ Log likelihood } & -875.77356 & \\
\hline \multicolumn{2}{|c|}{ Wald chi2(9) } & 82.57 & \\
\hline \multicolumn{2}{|c|}{ Prob>chi2 } & $<0.001$ & \\
\hline
\end{tabular}

Note: IRR incidence rate ratio, SDAQ single-disease with abundant quota, SDLQ single-disease with limited quota, \#, reference group. According to the Hausman test $(\mathrm{chi} 2(8)=5.00$, Prob $>$ chi $2=0.757)$, we use the random effect model

promising scenario, different kinds of IDNs were promoted across the county to facilitate the cooperation of different institutions with shared responsibility and benefits [71]. However, the tight IDNs reduced surgical care provision, indicating that the coordination between CLHs and THs did not perform as expected. It reminds us that the CLHs must be strictly regulated and that addressing the urgent need of the THs must be a priority during the establishment of IDNs. Additionally, positive effect of PRP on the appendectomy care provision indicates that improve the economic incentive of physicians would attract other physicians to provide surgical services. Hence, the economic leverage should be substantially developed to reduce burnout [72]. Considering the "ambivalent" compensation system for medical staff in China, in remote or rural areas with poor capacity and for specific population, the medical staff should be precisely targeted for empowerment [45, 73].

\section{Conclusion}

To the best of our knowledge, as the first research that attempted to ascertain challenges for surgical care provision in rural China, this insightful study is significant to researchers, policy makers, and THs' administrators. The current study offers helpful suggestions to facilitate the recovery of the capacity of the rural health system. Surgical services are under unprecedented challenges with a deteriorating trend. The surgical capacity is also under decline because of the inadequate motivation in both salaries and promotion and system deficiency. Considering that healthcare supply has been lagged by the dynamic demand and the payment methods for physicians are hysteretic to the supply, current and following policies should begin from the autonomous capacity building. Moreover, retention and recruitment of medical staff must be considered as priorities.

\section{Limitations}

Given that the first part of our study is limited to quality and accessibility of claim data, we only analyzed data from the DY and ZJ to describe trends in the surgical care provision. Further exploration should concentrate on the regular assessment of the transition base on large amounts of THs, as well as targeted interventions and capacity building.

\section{Acknowledgements \\ We thank all of officers and medical staff involved in this study. And we would not finish this study without their generous assistance.}

\section{Funding}

The Natural Science Foundation of China (71673099).

The Natural Science Foundation of China (71734003).

Availability of data and materials

All data and material is available upon reasonable request.

\section{Authors' contributions}

$L Z, Z L$, JY designed this study, ZL, JY, YW, ZP, XH collected and analyzed the data, and interpreted the results. ZL drafted the manuscript, $B L$ and $L Z$ helped to modify it. All authors read and approved the final manuscript.

Ethics approval and consent to participate

None

\section{Consent for publication}

All authors consent for publication.

Competing interests

The authors declare that they have no competing interest.

\section{Publisher's Note}

Springer Nature remains neutral with regard to jurisdictional claims in published maps and institutional affiliations.

\section{Author details}

'School of Medicine and Health Management, Tongji Medical College, Huazhong University of Science and Technology, No 13 Hangkong Road, Qiaokou District Wuhan, Hubei 430030, China. ${ }^{2}$ Department of Medical Affairs, Guangdong General Hospital, Guangzhou 510080, Guangdong, China.

Received: 9 October 2017 Accepted: 16 April 2018

Published online: 02 May 2018

References

1. Taira BR, Cherian MN, Yakandawala H, Kesavan R, Samarage SM, Desilva M. Survey of emergency and surgical capacity in the conflict-affected regions of Sri Lanka. World J Surg. 2010;34:428-32. 
2. Funk LM, Weiser TG, Berry WR, Lipsitz SR, Merry AF, Enright AC, Wilson $\mathbb{H}$, Dziekan G, Gawande AA. Global operating theatre distribution and pulse oximetry supply: an estimation from reported data. Lancet. 2010;376:1055.

3. Jamison DT, Breman JG, Measham AR, Alleyne G, Claeson M, Evans DB, Jha $P$, Mills A, Musgrove P. Priorities for global Research and Development of interventions - disease control priorities in developing countries. Pediatr Infect Dis J. 2006;27:suppl 1.

4. Farmer PE, Kim JY. Surgery and Global Health: a view from beyond the OR. World J Surg. 2008:32:533.

5. Listed N. Global surgery-the final frontier? Lancet. 2012;379:194.

6. Memon AS. Rural surgery in Pakistan. World J Surg. 2006;30:1628.

7. Kalkum M. Surgical problems in rural Germany. World J Surg. 2006;30:1630-1.

8. Harris JD, Hosford CC, Sticca RP. A comprehensive analysis of surgical procedures in rural surgery practices. Am J Surg. 2010;200:820-6.

9. Doty B, Zuckerman R, Finlayson S, Jenkins P, Rieb N, Heneghan S. How does degree of rurality impact the provision of surgical services at rural hospitals? J Rural Health. 2008;24:306-10.

10. O'Neill KM, Greenberg SL, Cherian M, Gillies RD, Daniels KM, Roy N, Raykar NP, Riesel JN, Spiegel D, Watters DA. Bellwether procedures for monitoring and planning essential surgical care in low-and middle-income countries: caesarean delivery, laparotomy, and treatment of open fractures. World J Surg. 2016;40:2611-9.

11. Lebrun DG, Saavedrapozo I, Agredaflores F, Burdic ML, Notrica MR, Mcqueen KA. Surgical and anesthesia capacity in Bolivian public hospitals: results from a national hospital survey. World J Surg. 2012;36:2559-66.

12. Meara JG, Hagander L, Leather AJM. Surgery and Global health: a lancet commission : the lancet. Lancet 2014, 383:12.

13. Linden AF, Sekidde FS, Galukande M, Knowlton LM, Chackungal S, Mcqueen KA. Challenges of surgery in developing countries: a survey of surgical and anesthesia capacity in Uganda's public hospitals. World J Surg. 2012;36: 1056-65.

14. Henry JA, Windapo O, Kushner AL, Groen RS, Nwomeh BC. A survey of surgical capacity in rural southern Nigeria: opportunities for change. World J Surg. 2012;36:2811-8.

15. Hadler RA, Chawla S, Stewart BT, Mccunn MC, Kushner AL. Anesthesia care capacity at health facilities in 22 low-and middle-income countries. World J Surg. 2016;40:1025-33.

16. Atiyeh BS, Gunn SWA, Hayek SN. Provision of essential surgery in remote and rural areas of developed as well as low and middle income countries. Int J Surg. 2010;8:581-5.

17. Clarke DL, Aldous C, Thomson SR. Assessing the gap between the acute trauma workload and the capacity of a single rural health district in South Africa. What are the implications for systems planning? Eur J Trauma \& Emerg Surg. 2014;40:303-8

18. Weiser TG, Regenbogen SE, Thompson KD, Haynes AB, Lipsitz SR, Berry WR, Gawande AA. An estimation of the global volume of surgery: a modelling strategy based on available data. Lancet. 2008:372:139-44.

19. Alkire BC, Raykar NP, Shrime MG, Weiser TG, Bickler SW, Rose JA, Nutt CT, Greenberg SLM, Kotagal M, Riesel JN. Global access to surgical care: a modelling study. Lancet Global Health. 2015;3:e316-e323.

20. Groen RS, Samai M, Petroze RT, Kamara TB, Yambasu SE, Calland JF Kingham TP, Guterbock TM, Choo B, Kushner AL. Pilot testing of a population-based surgical survey tool in Sierra Leone. World J Surg. 2012;36:771-4.

21. Bae JY, Groen RS, Kushner AL. Surgery as a public health intervention: common misconceptions versus the truth. Bull World Health Organ. 2011;89:395

22. Godden D. Rural health care in the UK: a rapidly changing scene. J Agric Saf Health. 2005;11:205-10.

23. Spiegel DA, Gosselin RA. Surgical services in low-income and middle-income countries. Lancet. 2007;370:1013-5.

24. Board WE. Strengthening emergency and essential surgical care and anaesthesia as a component of universal health coverage. 20 March 2015

25. WHO: PRIMARY SURGICAL CARE PACKAGE (PSCP). 2015.

26. Bickler SW, Spiegel D. Improving surgical Care in low- and Middle-Income Countries: a pivotal role for the World Health Organization. World J Surg. 2010;34:386

27. Hsiao WC. The Chinese health care system: lessons for other nations. Soc Sci Med. 1995;41:1047-55.

28. Ho LS. Market reforms and China's health care system. Soc Sci Med. 1995;41:1065-72.
29. Liu Y, Hsiao WC, Eggleston K. Equity in health and health care: the Chinese experience. Soc Sci Med. 1999;49:1349.

30. Hsiao WC. Disparity in health: the underbelly of China's economic development. Harvard China Review. 2004;5(1):64-70.

31. Hsiao WC. When incentives and professionalism collide. Health Aff. 2008;27:949.

32. Yip W, Hsiao W. Harnessing the privatisation of China's fragmented health-care delivery. Lancet. 2014;384:805.

33. Yip CM, Hsiao WC, Chen W, Hu S, Ma J, Maynard A. Early appraisal of China's huge and complex health-care reforms. Lancet. 2012;379:833.

34. Iglesias S, Tepper J, Ellehoj E, Barrett B. Rural surgical services in two Canadian provinces. Can J Rural Med. 2006;11:207.

35. Zhang Y, Chen Y, Zhang X, Zhang L. Current level and determinants of inappropriate admissions to township hospitals under the new rural cooperative medical system in China: a cross-sectional study. BMC Health Serv Res. 2014;14:649.

36. World Bank Group, World Health Organization, Ministry of Finance, National Health and Family Planning Commission, Ministry of Human Resources and Social Security. Health China: Deepening health reform in China building high-quality and value-based service quality. Available from: https:// openknowledge.worldbank.org/bitstream/handle/10986/24720/ HealthReformlnChina.pdf. Accessed 29 Apr 2018.

37. Bhattacharyya O, Delu Y, Wong ST, Bowen C. Evolution of primary care in China 1997-2009. Health policy. 2011;100:174-80.

38. National Health and Family Planning Commission. An Analysis Report of National Health Services Survey in China; 2013. p. 2015.

39. National Health and Family Planning Commission. China Health Statictics Yearbook [M]. 2016

40. Meng $Q$, Jing $Y$, Jing $L$, Zhang J. Mobility of primary health care workers in China. Hum Resour Health. 2009;7:24.

41. Yang L, Sun L, Wen L, Zhang H, Li C, Hanson K, Fang H. Financing strategies to improve essential public health equalization and its effects in China. Int J Equity Health. 2016;15:194

42. Jian W, Li X, Yao S, Hui S, Qian S, Qin D, Xie S, Shi L. The impact of a bundled policy intervention on improving the performance of rural healthcare in China. Int J Equity Health. 2016;15:46.

43. Yan K, Jiang Y, Qiu J, Zhong X, Wang Y, Deng J, Lian J, Wang T, Cao C. The equity of China's emergency medical services from 2010-2014. Int J Equity Health. 2017;16:10.

44. National Bureau of Statistics. The Six National Census Report. 2011.

45. UNDP. China National Human Development Report; 2016. p. 2016.

46. Wang L. A comparison of metropolitan and rural medical schools in China: which schools provide rural physicians? Aust J Rural Health. 2002;10:94-8.

47. Shi L, Makinen M, Lee DC, Kidane R, Blanchet N, Liang H, Li J, Lindelow M, Hong W, Xie S. Integrated care delivery and health care seeking by chronically-ill patients - a case-control study of rural Henan province, China. Int J Equity Health. 2015;14:1-15.

48. Wang X, Birch S, Ma H, Zhu W, Meng Q. The structure and effectiveness of health systems: exploring the impact of system integration in rural China. Int J Integrated Care. 2016;16:6

49. Lemak CH, Nahra TA, Cohen GR, Erb ND, Paustian ML, Share D, Hirth RA. Michigan's fee-for-value physician incentive program reduces spending and improves quality in primary care. Health Aff. 2015;34:645-52.

50. Hung LM, Shi L, Wang H, Nie X, Meng Q. Chinese primary care providers and motivating factors on performance. Fam Pract. 2013:30:576-86.

51. Luck J, Peabody J, DeMaria L, Alvarado C, Menon R. Patient and provider perspectives on quality and health system effectiveness in a transition economy: evidence from Ukraine. Soc Sci Med. 2014;114:57-65.

52. Sharma $R$, Webster $P$, Bhattacharyya $S$. Factors affecting the performance of community health workers in India: a multi-stakeholder perspective. Glob Health Action. 2014;7:25352.

53. He Z, Cheng Z, Fu H, Tang S, Fu Q, Fang $H$, Xian Y, Ming H, Feng Z. Factors associated with the competencies of public health workers in township hospitals: a cross-sectional survey in Chongqing municipality, China. Int J Environ Res Public Health. 2015;12:14244-59.

54. Spiegel DA, Abdullah F, Price RR, Gosselin RA, Bickler SW. World Health Organization global initiative for emergency and essential surgical care: 2011 and beyond. World J Surg. 2013;37:1462-9.

55. Hoyler M, Finlayson SR, McClain CD, Meara JG, Hagander L. Shortage of doctors, shortage of data: a review of the global surgery, obstetrics, and anesthesia workforce literature. World J Surg. 2014;38:269-80. 
56. Greene W. Functional form and heterogeneity in models for count data. Foundations and Trends ${ }^{\oplus}$. Econometrics. 2007;1:113-218.

57. Greene WH. Accounting for excess zeros and sample selection in Poisson and negative binomial regression models. 1994.

58. Greene W. Functional forms for the negative binomial model for count data. Econ Lett. 2008;99:585-90.

59. Lee AH, Wang K, Yau KK, Somerford PJ. Truncated negative binomial mixed regression modelling of ischaemic stroke hospitalizations. Stat Med. 2003;22:1129-39.

60. Hartert TV, Neuzil KM, Shintani AK, Mitchel EF, Snowden MS, Wood LB, Dittus RS, Griffin MR. Maternal morbidity and perinatal outcomes among pregnant women with respiratory hospitalizations during influenza season. Am J Obstet Gynecol. 2003;189:1705-12

61. Jin Y, Zhu W, Yuan B, Meng Q. Impact of health workforce availability on health care seeking behavior of patients with diabetes mellitus in China. Int J Equity Health. 2017;16:80.

62. Hausman JA. Specification tests in econometrics. Econometrica. 1978:1251-71.

63. Yip W, Hsiao WC. What drove the cycles of Chinese health system reforms? Health Systems \& Reform. 2015;1:52-61.

64. Dupree JM, Patel K, Singer SJ, West M, Wang R, Zinner MJ, Weissman JS. Attention to surgeons and surgical care is largely missing from early medicare accountable care organizations. Health Aff. 2014;33:972-9.

65. Virginie $P$, Andrew R, Joanne LE. Creating a patient-centered health care delivery system: a systematic review of health care quality from the patient perspective. Am J Med Qual Official J Am Coll Med Qual. 2016;31:12.

66. Vetter TR, Boudreaux AM, Jones KA, Jr HJ, Pittet JF. The perioperative surgical home: how anesthesiology can collaboratively achieve and leverage the triple aim in health care. Anesth Analg. 2014;118:1131-6.

67. H-q S, Y-p B, S-j Z, S-q M, Lu L. The new pattern of drug abuse in China. Curr Opin Psychiatry. 2014;27:251-5.

68. Qian D, Pong RW, Yin A, Nagarajan KV, Meng Q. Determinants of health care demand in poor, rural China: the case of Gansu Province. Health Policy Planning. 2009;24:324.

69. Wang C, Lang J, Xuan L, Li X, Zhang L. The effect of health literacy and selfmanagement efficacy on the health-related quality of life of hypertensive patients in a western rural area of China: a cross-sectional study. Int J Equity Health. 2017:16:58

70. Wu Y, Zhang L, Liu X, Ye T, Wang Y. Geographic variation in health insurance benefits in Qianjiang District, China: a cross-sectional study. Int J Equity Health. 2018;17:20.

71. Wang L. County integrated healthcare organization, China solution of rural health. Chinese Studies. 2017;6:161.

72. Shipman SA, Sinsky CA. Expanding primary care capacity by reducing waste and improving the efficiency of care. Health Aff. 2013;32:1990-7.

73. Lavergne MR, Law MR, Peterson S, Garrison S, Hurley J, Cheng L, McGrail K. A population-based analysis of incentive payments to primary care physicians for the care of patients with complex disease. Can Med Assoc J. 2016;188:E375-83.

\section{Ready to submit your research? Choose BMC and benefit from:}

- fast, convenient online submission

- thorough peer review by experienced researchers in your field

- rapid publication on acceptance

- support for research data, including large and complex data types

- gold Open Access which fosters wider collaboration and increased citations

- maximum visibility for your research: over $100 \mathrm{M}$ website views per year

At BMC, research is always in progress.

Learn more biomedcentral.com/submissions 